\title{
REMEMORAR É TRANSCENDER: UM DIÁLOGO COM LICENCIANDOS DO GRUPO PET CONEXÕES DE SABERES DA UNIVERSIDADE FEDERAL FLUMINENSE
}

\author{
RECORDAR ES TRANSCENDER: UN DIÁLOGO CON LICENCIANTES DEL GRUPO \\ PET CONEXIONES DE CONOCIMIENTOS DE LA UNIVERSIDAD FEDERAL \\ FLUMINENSE
}

\section{REMEMBERING IS TRANSCENDING: A DIALOG WITH GRADUATE STUDENTS IN TEACHER TRAINING PROGRAM OF PET GROUP CONNECTIONS AND KNOWLEDGE AT FLUMINENSE FEDERAL UNIVERSITY}

\author{
Cyntia de Souza Bastos REZENDE ${ }^{1}$ \\ Mônica VASCONCELLOS ${ }^{2}$
}

\begin{abstract}
RESUMO: Este trabalho tem por objetivo analisar narrativas de licenciandos acerca das contribuições do Grupo PET Conexões de Saberes da Universidade Federal Fluminense (UFF) para a formação e a produção de saberes profissionais dos envolvidos. Com enfoque qualitativo, do tipo estudo de caso, o universo investigado foi composto por 4 licenciandos, bolsistas do referido Grupo, que a ele estiveram vinculados entre os anos de 2014 e 2018. As informações foram coletadas por meio de entrevistas pautadas por um roteiro semiestruturado, caderno de campo e observações das reuniões realizadas nos encontros semanais. Também foram analisados documentos oficiais que respaldam legalmente o Programa de Educação Tutorial/MEC-SESu e materiais que norteiam a criação e o desenvolvimento do trabalho realizado pelo Grupo selecionado. Os resultados evidenciam produção e articulação de saberes docentes produzidos na universidade e na escola, compartilhamento de ações de natureza profissional, ressignificação dos conhecimentos teóricos estudados e desenvolvimento de um olhar investigativo sobre sua futura profissão. Apontam, ainda, que a participação no Grupo citado amplia e reforça as chances de permanência na universidade devido ao sentimento de coletividade, de acolhimento pessoal e de pertencimento no sentido profissional, bem como em razão do apoio financeiro que os licenciandos recebem do Programa, mediante o pagamento de uma bolsa.
\end{abstract}

PALAVRAS-CHAVE: Formação inicial. Programa de Educação Tutorial. Saberes docentes. Profissão docente.

RESUMEN: Este trabajo tiene como objetivo analizar narrativas de pregrado sobre las contribuciones del Grupo PET Conexiones de conocimientos de la Universidad Federal Fluminense (UFF) para la formación y producción de conocimientos profesionales de los involucrados. Con un enfoque cualitativo, del tipo de estudio de caso, el universo investigado estaba compuesto por 4 estudiantes universitarios, becarios del Grupo que estuvo vinculado a él entre 2014 y 2018. Las informaciones fueron recolectados através de entrevistas guiadas por un guión semiestructurado, diario de campo y observaciones de las reuniones realizadas en las reuniones semanales. También fueron analizados documentos oficiales que respaldan legalmente el Programa de Educación Tutorial/MEC-SESu y materiales que guían la creación y el desarrollo del trabajo realizado por el

1 Universidade Federal Fluminense (UFF), Niterói - RJ - Brasil. Doutoranda em Educação. ORCID: https://orcid.org/0000-0003.1719-6145. E-mail: cyntiagaleao.faeterj@gmail.com

${ }^{2}$ Universidade Federal Fluminense (UFF), Niterói - RJ - Brasil. Professora da Faculdade de Educação e do Programa de Pós-graduação em Educação. Doutora em Educação. ORCID: https://orcid.org/0000-0003-29382121. E-mail: monicavasconcellos@id.uff.br 
Grupo seleccionado. Los resultados muestran producción y articulación de conocimientos docentes producidos en la universidad y en la escuela, compartiendo acciones de naturaliza profesional, resignificación de conocimientos teóricos estudiados y desarrollo de uma mirada investigativa sobre tu futura profesión. También señalan la participación en el Grupo mencionado aumenta y refuerza las posibilidades de estancia universitaria debido a la sensación de recepción personal y pertenencia en el sentido profesional, así como la razón del apoyo financiero que los estudiantes universitarios reciben del Programa, previo pago de una beca.

PALAVRAS-CLAVE: Formación inicial. Programa de Educación Tutorial. Conocimientos docentes. Profesión docente.

ABSTRACT: This work aims at analyzing narratives produced by undergraduate students in teacher training programs about the contributions of the PET Group "Connections and Knowledge" in the formation and production of knowledge of the professionals engaged. Presenting a qualitative approach, of the case-study type, the group was formed by 4 undergraduate students in teacher training, who were also scholarship holders of the above mentioned group (PET) during the period comprised by the years of 2014 and 2018. The data was collected via semistructed interviews, field researcher's notes, observation of the meetings performed by the Group weekly. There was also the analysis of official documents which legally support the Program of Educational Tutoring/MEC-SESu, and materials which guide work creation and development of the above mentioned Group. The results make clear the production and the articulation of teachers' knowledge both at university and at school, the sharing of activities which are professional in nature, the resignification of theoretical knowledge, and the development of a more investigative approach to the future career. These results also indicated that the participation of this particular Group increased and reinforced the chances of these students staying at university due to a sense of community, of personal welcoming and of belonging in a more professional aspect; as well as the financial help these students obtain from participating in the program via scholarship.

KEYWORDS: Initial formation. Program of Educational Tutoring. Teaching knowledge. Teaching career.

\section{Introdução}

O trabalho apresentado é parte de uma pesquisa de mestrado defendida em março de 2019, e tem como pano de fundo questões que dizem respeito à relação entre formação inicial e profissão docente, sobretudo suas motivações e interesses expressos em narrativas que foram sendo tecidas pelos licenciandos participantes do Programa de Educação Tutorial da Universidade Federal Fluminense.

As reflexões aqui desenvolvidas se apoiam em estudos sobre a problemática dos saberes e práticas formativas, levando em conta que a sociedade vem passando por transformações que alteram as relações de trabalho em diversos campos profissionais, introduzindo novas compreensões sobre carreira e desenvolvimento profissional (GATTI, 2009). Essas novas perspectivas vêm substituindo empregos estáveis e modelos de remuneração por formas mais flexíveis e precarizadas de contrato que não garantem a 
estabilidade do emprego a longo prazo. Nas palavras de Gatti (2009, p. 9-10), esta temática requer aprofundamento, tendo em vista "[...] que os contextos sociais em transformação interferem nas relações entre o indivíduo e o social e, desse modo, nas identidades sociais e profissionais".

Com intuitos diferentes, políticas e programas voltados para a formação docente chegam às Instituições de Ensino Superior (IES) do Brasil acompanhados pelo discurso da melhoria da formação dos licenciandos. Algumas dessas ações geraram nos últimos anos impactos satisfatórios aos olhos de boa parte da comunidade acadêmica e escolar. Dentre elas, destacamos o Programa de Bolsas de Iniciação à Docência (PIBID), implantado em 2007 pela Coordenação de Aperfeiçoamento de Pessoal de Nível Superior (CAPES)/Fundo Nacional de Desenvolvimento da Educação $(\mathrm{FNDE})^{3}$. Este Programa tem sido acompanhado por pesquisadores de diferentes instituições que apresentam resultados positivos a propósito das articulações que provoca entre a formação e a profissão, ocasionando nos licenciandos a percepção de que contribui fortemente para a constituição de aprendizagens ligadas ao magistério (VICENTE; VASCONCELLOS, 2014).

Além de envolver as próprias escolas na mobilização dos professores que assumem a função de coformadores dos licenciandos, o encaminhamento do trabalho contribui para a melhor articulação entre teoria e prática, “[...] elevando a qualidade das ações acadêmicas nos cursos de licenciatura" (BRASIL, 2010, art. $3^{\circ}$, inciso VI).

Outras contribuições são a valorização do magistério e o incentivo à formação docente em nível superior em estreita ligação com a educação básica, tendo por metas: inserir os licenciandos no cotidiano das escolas das redes públicas de ensino, propiciando

[...] oportunidades de criação e participação em experiências metodológicas, tecnológicas e práticas docentes de caráter inovador e interdisciplinar que busquem a superação de problemas identificados no processo de ensinoaprendizagem (BRASIL, 2010, art. $3^{\circ}$, inciso IV).

Parte dos estudos relacionados a este assunto aponta que o desenvolvimento das ações propostas por este Programa suscita a valorização dos próprios cursos no interior das instituições que os acolhem (GATTI, 2015).

Se o PIBID tem recebido forte atenção por parte dos pesquisadores da área da Educação, o mesmo não podemos dizer em relação ao Programa de Educação Tutorial (PET). Criado em 1979 pelo Ministério da Educação e Cultura, o PET teve desde a origem o intuito de qualificar e fortalecer o Ensino Superior no Brasil por meio da composição de grupos

\footnotetext{
${ }^{3}$ Disponível em: http://www.capes.gov.br/educacao-basica/capespibid/pibid. Acesso em: jan. 2018.
} 
formados por um(a) tutor(a) e até 18 estudantes que propõem e desenvolvem, anualmente, um plano de atividades que articule ações ligadas à pesquisa, ao ensino e à extensão. Dados de 2016 dão conta de que na época o PET abrangia 842 grupos distribuídos entre 121 Instituições de Ensino Superior, totalizando aproximadamente 15.000 alunos de diferentes áreas de formação profissional ${ }^{4}$, tais como Medicina, Engenharias, Farmácia, Economia, Geografia, Odontologia, entre outras. Em nosso caso, o Grupo PET Conexões de Saberes, chamado carinhosamente pelos seus membros de PET Licenciaturas, foi formado no segundo semestre de 2014 e, na ocasião desta pesquisa, contava com 18 licenciandos dos cursos de História, Geografia, Letras, Pedagogia e Matemática que desenvolviam ações na Universidade Federal Fluminense (UFF) e em escolas públicas localizadas no município de Niterói/RJ. Este Grupo traz consigo o fato de ser o primeiro a funcionar na Faculdade de Educação da mesma Universidade (FEUFF) e ser o único voltado para a formação docente.

Esta especificidade e os resultados parciais produzidos nos moveram a questionar: em que medida os membros do Grupo PET-Licenciaturas têm produzido saberes profissionais do campo do magistério? Quais seriam estes saberes e de que modo contribuem para sua formação nos cursos de origem?

Estudos desenvolvidos por Tardif (2014, p. 21) expressam que “[...] Ensinar é mobilizar uma ampla variedade de saberes, reutilizando-os no trabalho para adaptá-los e transformá-los pelo e para o trabalho". Esta afirmação reforça a ideia de que os saberes profissionais dos professores são constituídos no decorrer de um processo que ocorre ao longo da trajetória de vida pessoal/profissional. Cabe advertir que investigar este tema não é tarefa fácil, pois envolve

[...] relações entre tempo, trabalho e aprendizagem [...] mobilizados e empregados na prática cotidiana, saberes esses que provém, de uma maneira ou outra, e servem para resolver os problemas dos professores em exercício, dando sentido às situações de trabalho que lhes são próprias (TARDIF, 2014, p. 58).

Compreende-se, de acordo com Tardif (2014), que os saberes dos professores não se limitam a conteúdos bem circunscritos que dependem de um conhecimento especializado, como também não dependem exclusivamente dos conhecimentos teóricos obtidos na universidade, e tampouco estão restritos à pesquisa educacional. Eles abrangem uma grande diversidade de objetos, questões e problemas que estão relacionados em seu trabalho.

${ }^{4}$ Estas informações estão disponíveis na Carta aprovada pela Assembleia Geral do XVI SUDESTEPET, em março de 2016 .

RIAEE - Revista Ibero-Americana de Estudos em Educação, Araraquara, v. 15, n. esp. 2, p. 1569-1584, ago. 2020. e-ISSN: $1982-5587$. DOI: https://doi.org/10.21723/riaee.v15iesp2.13829 
Na busca por compreender este processo de formação de caráter múltiplo e entender a aquisição de conhecimentos para o reconhecimento de si como professor é que a formação inicial do futuro docente, ocasionada pela participação no Programa de Educação Tutorial/PET, mais especificamente, no Grupo PET - Conexões de Saberes, tornou-se objeto da pesquisa.

Tendo em vista nosso foco de investigação, desenvolvemos nossa dissertação de mestrado com a finalidade de analisar narrativas de licenciandos acerca das contribuições do Grupo PET - Conexões de Saberes para a formação e a produção de saberes profissionais dos envolvidos. A conclusão desta pesquisa ocorreu no primeiro semestre de 2019 e parte dos dados produzidos originaram este artigo. Diante da impossibilidade de abordarmos todas as informações coletadas, optamos por contemplar parte de uma delas: "Saberes e Práticas Pedagógicas nas Licenciaturas".

\section{Um caminho percorrido: uma experiência teórico-metodológica}

Os estudos desenvolvidos por Bernardete Gatti (2009) indicam que a docência vem deixando de ser uma opção profissional procurada pelos jovens e destaca a urgência de discutirmos e tomarmos providências que nos levem a superar os fatores que interferem no decréscimo da demanda pela carreira. "A questão é importante porque o desenvolvimento social e econômico depende da qualidade da escolarização básica, mais ainda na emergência da chamada sociedade do conhecimento" (p. 7).

No caso da nossa pesquisa, supomos que os resultados identificados podem nos oferecer perspectivas para a formação inicial de professores que apontem possibilidades de diminuição de parte dos entraves vividos na formação inicial e no ingresso na carreira, favorecendo a permanência dos novos docentes na profissão.

O percurso metodológico da presente pesquisa abrangeu 4 dos 12 petianos que iniciaram seus trabalhos com o Grupo PET - Licenciaturas, em 2014. A motivação para a escolha desses sujeitos ocorreu utilizando como critérios o ano de vinculação ao Grupo (2014) e o mínimo de 3 anos e meio de permanência, o que nos levou a este total.

A redução partiu do princípio de que para se trabalhar com narrativas, que segundo Clandinin e Connely (2000, p. 20), constituem "[...] uma forma de entender a experiência", não seria viável envolver um número expressivo de participantes, tendo em vista o considerável volume de informações que produziríamos e analisaríamos em curto espaço de tempo, uma vez que contávamos com apenas dois anos para a conclusão do mestrado. 
Dentre os 4 petianos selecionados para a pesquisa, a única que foi escolhida por um critério diferente dos demais foi Tamires, que esteve diretamente vinculada ao Grupo PET por 2 anos. Esta opção se deve ao fato de que, ainda no período inicial do mestrado, enquanto aguardava o momento de orientação, Tamires, que conversava com a orientadora da pesquisa, desabafou espontaneamente que seu envolvimento no PET foi fundamental para a superação de problemas pessoais e acadêmicos que contribuíram, inclusive, para sua escolha profissional. Seu depoimento foi decisivo por ter despertado $\operatorname{minha}^{5}$ curiosidade sobre a natureza desse Grupo e pelo tipo de trabalho que desenvolvem, a ponto de exercer tamanha influência sobre uma jovem que, embora permanecesse próxima à Tutora e aos demais integrantes, na época já não estava mais vinculada ao Grupo. Foi neste contexto que o objeto de pesquisa "saltou aos meus olhos", e esta investigação passou a fazer parte do nosso campo de interesse.

Tomada a decisão, partimos para o estudo da bibliografia que compõe o corpo teórico de nossa pesquisa e, em paralelo, fomos delineando os objetivos, a metodologia e elegemos os sujeitos que a ela seriam integrados. De posse dessas definições, aos 4 selecionados fizemos um convite, via mensagem por aplicativo de celular, para que participassem da pesquisa mediante realização de uma entrevista semiestruturada, a fim de levantarmos informações em torno do objeto em questão. Para tanto, previamente, a Tutora do Grupo pediu autorização aos mesmos para que os números de seus telefones fossem fornecidos. Como todos concordaram, na mensagem que enviamos individualmente explicamos os objetivos da investigação e, de comum acordo, acertamos as datas das entrevistas individuais. As entrevistas foram realizadas com base em um roteiro semiestruturado e gravadas com o auxílio de um gravador de áudio do celular. O roteiro foi composto por duas partes que se subdividiam em 4 blocos.

A primeira parte, denominada "Perfil", era constituída por 3 blocos: Identificação; Vida escolar e Graduação/Licenciatura. De forma ampla, os blocos continham perguntas sobre a idade e os contatos pessoais dos entrevistados; o tipo de escola frequentada durante o ensino fundamental e médio, bem como os motivos que os levaram a eleger o curso de licenciatura em andamento e possíveis influências para esta decisão.

A segunda parte do roteiro abarcou 15 perguntas que compuseram um bloco sobre a participação dos sujeitos no Grupo PET. Dentre as indagações formuladas pedimos que nos esclarecessem: Como ficou sabendo sobre o Grupo PET - Conexões de Saberes e por que decidiu participar do processo de seleção; ano de ingresso no Grupo e justificativas para sua

${ }^{5}$ Por se tratar de um aspecto de natureza pessoal, optamos por registrar esta informação na primeira pessoa do singular. 
permanência ou não; considerações sobre a profissão de professor antes de ingressar no Grupo e possíveis mudanças de ponto de vista; problemas e desafios profissionais vividos com o PET, bem como possíveis estratégias de superação; tipos de contribuição desencadeadas (de caráter pessoal, acadêmico, político, profissional e etc.) por meio do trabalho desenvolvido enquanto esteve no Grupo; intenção de ingressar e/ou permanecer no magistério e perspectivas profissionais; possíveis relações entre os estudos e as atividades desenvolvidas com o Grupo PET Conexões de Saberes e a permanência nos cursos de licenciatura.

A escolha pela entrevista como procedimento de coleta de informações partiu da necessidade incitada pelos objetivos da investigação que em sua redação evidenciam a relevância da escuta dos sujeitos. Aliada a esta questão nos sentimos interessadas em aprofundar e ampliar os dados coletados por outros instrumentos, para que pudéssemos analisá-los sob diferentes perspectivas e nos aproximarmos da sua totalidade. Esse aprofundamento possibilitou alcançar os participantes através dos seus discursos sobre o tema da pesquisa e descrever as percepções, representações, conceitos, valores e suas histórias de vida de modo mais coerente e claro, a partir do que os entrevistados apresentaram em seus depoimentos (MATTOS; CASTRO, 2010).

Mattos e Castro (2010, p. 95) agregam informações pertinentes às questões dessa natureza, conforme revela o excerto:

Ao narrar sobre sua história de vida [e experiências] uma pessoa tende a selecionar detalhes para mostrar ao entrevistador como ele faz sentido de algo que julga ser importante para o desenvolvimento da pesquisa deste. $\mathrm{O} / \mathrm{a}$ entrevistado/a tem consciência de que o/a entrevistador/ra precisa compreender alguma coisa sobre esta história de vida. O entrevistador tem consciência de que a parte da história que está sendo revelada pode não refletir o momento que está sendo vivido por ambos - entrevistador e entrevistado, mas que é necessário fazer sentido daquele momento. De modo que a história [e/ou experiência] trazida à tona pelo entrevistado precisa ser respeitada e seu significado preservado em termos da contextualização evocada por ele/ela que pode tanto ser posterior quanto anterior ao fato narrado.

O caráter de interação e sensibilidade explicitado no excerto anterior foi foco de nossa atenção antes, durante e após a implementação de cada entrevista, e nos levou a criar uma atmosfera de influência recíproca entre quem pergunta e quem responde, tornando o roteiro passível de alterações durante o processo (LÜDKE; ANDRÉ, 2004).

$\mathrm{O}$ encontro com as narrativas dos diferentes sujeitos nos revelou uma diversidade de argumentos e posicionamentos que, ao serem analisados, possibilitaram uma ampla leitura 
dos seus entendimentos a propósito dos processos de produção de sentidos, de construção de conhecimentos, de opiniões sobre suas histórias de vida e os elos que foram se estabelecendo com a docência. O volume, a qualidade e a diversidade das respostas adquiridas foram consideráveis, e para que pudéssemos analisá-las, algumas anotações foram feitas no diário de bordo durante a própria entrevista, visando futuras categorizações e o estabelecimento de relações com a literatura. Ao término deste processo, transcrevemos os depoimentos ouvindo um a um os áudios de cada entrevistado. Para além das transcrições, o ato de ouvir e tornar a ouvir suas falas possibilitou a revisão das ideias abordadas que, no calor das entrevistas, nem sempre ficam claras. Esta retomada contínua dos áudios também favoreceu a identificação de trechos significativos que posteriormente foram analisados (SPINK et al., 2014).

Este material foi categorizado por meio de análise de conteúdo, a partir da compreensão de que a mesma é, frequentemente, empregada para ressaltar palavras, frases e expressões de acordo com o objetivo da pesquisa (BARDIN, 1996).

Para Gil (2008, p. 152),

A exploração do material constitui, geralmente, uma fase longa e fastidiosa que tem como objetivo administrar sistematicamente as decisões tomadas na pré-análise. Refere-se fundamentalmente às tarefas de codificação, envolvendo: o recorte - escolha das unidades, a enumeração - escolha das regras de contagem e a classificação - escolha de categoria.

De acordo com o autor (Ibidem, 2008, p. 177), “[...] a análise dos dados na pesquisa qualitativa passa a depender muito da capacidade e do estilo do pesquisador", portanto, nesta etapa é importante tomar decisões acerca da maneira como as categorias serão codificadas, agrupadas e organizadas para que as conclusões se tornem razoavelmente estabelecidas e verificáveis. Portanto, a análise de conteúdo não é a última fase do processo de pesquisa, mas, de certo modo, concomitante à coleta de dados, pois essas duas etapas se comunicam, o que torna o processo de análise sistemático, compreensivo e flexível (TESCH, 1990 apud GIL, 2008).

\section{Trajetórias de vida e formação: narrativas do tempo presente}

A preocupação com a educação escolar nos leva a pensar e a buscar a constituição de relações pedagógicas intencionais desenvolvidas por professores profissionais que considerem em seu cotidiano de trabalho as mais diversas configurações sociais e suas demandas. Isso exige repensar novas didáticas que possam provocar aprendizagens distintas entre/com os diferenciados grupos de estudantes. A esse respeito, Gatti (2013, p. 55) salienta que: "É 
necessário transcender o senso comum reificado, superando os sentidos usuais atribuídos às práticas pedagógicas condenadas".

Corroborando as considerações da pesquisadora e provocadas pelas razões apresentadas, nos sentimos instigadas a conhecer o trabalho voltado para a formação inicial de professores realizado pelo Grupo PET Conexões de Saberes da UFF. Esse Grupo estuda, elabora e desenvolve projetos interdisciplinares em escolas municipais de Niterói/RJ desde 2014. Para compreender as minúcias do trabalho que desenvolvem e contemplar os objetivos delineados contamos com a colaboração de Thaís, Tamires, Vinicius e Davi.

Dentre os $4^{6}$ entrevistados, Vinícius e Davi permaneceram no referido Grupo até o final da graduação (dezembro de 2017). Thaís, por questões pessoais, saiu em dezembro de 2017, isto é, 2 semestres antes da conclusão de sua licenciatura e Tamires, que esteve integrada por 2 anos, se desligou no primeiro semestre de 2017 por ter sido aprovada no processo seletivo para o Programa de Bolsas de Iniciação Científica (PIBIC).

As análises das respostas fornecidas deram origem a 3 categorias formuladas em acordo com os objetivos da investigação, porém, frente às restrições impostas à escrita do artigo, neste trabalho fazemos menção às informações abarcadas por uma delas: "Saberes e Práticas Pedagógicas nas Licenciaturas". Embora esta categoria seja composta por 5 perguntas, somente duas delas foram abordadas em virtude das mesmas razões: "Profissão Docente" e "Práticas Formativas das Licenciaturas".

A partir das narrativas dos entrevistados, buscamos evidenciar os sentidos profissionais dos envolvidos articulando-os às ações e aos estudos realizados pelo Grupo. Aos entrevistados perguntamos o que pensavam sobre a profissão de professor antes e depois da participação no Grupo PET e caso sua opinião tenha sido alterada no referido período, pedimos que explicitassem quais foram as situações/experiências que interferiram nesta mudança.

Na visão de Thaís, participar do Grupo PET favoreceu a compreensão do que é ser professor. Visão esta que ainda não havia experimentado nos estágios. Nas palavras da estudante:

[..] agora eu me encontrava numa sala de aula a frente de uma turma, mas mudou a concepção do que é ser professor. E eu descobri que ser professor, não é só ser professor, mas é muito mais. Assim.... [Pausa com respiração forte] como eu falei nas matérias de Educação, na PPE, eu fui para a sala de aula, eu tive um contato com a escola, mas com o PET é parecido o contato, mas ele me trouxe experiências e visões diferentes do que é a sala de aula.

${ }^{6}$ Os entrevistados deram autorização por escrito para que seus nomes fossem mantidos na pesquisa. 
Aí, eu entendi na prática, o que é ser um professor. Óbvio que em todo o período do projeto, a gente não fica somente o Grupo PET e a turma, sempre tem a presença dos professores ali com a gente, sempre tem essa interação, essa troca dos professores [...]. Isso para mim foi um divisor de águas, assim, na minha decisão em ser professora e desenvolver o trabalho de professora que não é só um trabalho, né? Mas são lições de vida que a gente aprende, a gente se forma. Porque no PET, a gente pesquisa muito, tem um embasamento teórico bem grande, antes da gente ir para o ambiente escolar, a gente estuda muito sobre ele, a gente lê sobre ele, nós pesquisamos olhares diferentes sobre a sala de aula, sobre o ambiente escolar. [...] É isso, é esse equilíbrio entre o conhecimento que você estuda, que você aprende através dos teóricos, de textos e afins, com a experiência vivida com a realidade da escola [...] (THAÍ́S, 2018).

Partindo da experiência de Tamires, o Grupo PET trouxe uma nova concepção do fazer do professor em sala de aula. Mostrou que para ensinar e ser um bom professor não bastava conhecer bem a matéria, transmiti-la e esperar que o aluno se mantivesse atento às suas explicações para que aprendesse. Nesse contexto de vivência junto ao Grupo, no período de aproximação com a escola, passou a estabelecer vínculos com os alunos e conhecer a realidade não só da sala de aula, mas também das relações entre os sujeitos, tornando esse momento fundamental para reconhecer que a profissão extrapola os limites do saber bem a matéria.

Então, para mim, antes do PET, eu achava que o professor era aquele que detinha o conhecimento. Enfim, a única função era a gente chegar na sala dar aula e pronto, não precisava discutir outras coisas além da matéria [...]. Essa concepção era a certa! Eu vou me formar, vou para uma escola e dar aula expositiva. Eu nem vou copiar no quadro, só falo! Vou entender o conteúdo e quem aprendeu, passo o exercício. E quem aprendeu, aprendeu! O que não aprendeu, paciência! Mas depois do PET, eu vi que a escola tinha outras concepções e que não era só a minha profissão que importava dentro do contexto escolar. Mas, os alunos, os problemas que surgem na escola, os problemas que surgem na casa dos alunos, os problemas que surgem na sociedade. Então, esses problemas, o PET me fez perceber o mundo que se cruza na escola [...]. Que a escola é o espaço de entrecruzamento de culturas. E aí, com essa questão do entrecruzamento foi onde que eu percebi que não era só minha profissão que importava no espaço escolar. Mas, as culturas! As diferentes culturas que surgiram! E aí então, eu pensei que... Nossa! Eu vou ser uma professora, mas eu não posso ser uma professora que simplesmente detém todo o conteúdo [...] (TAMIRES, 2018).

Verificamos a partir dos relatos que a compreensão sobre a profissão de professor foi sendo ampliada/reformulada/ressignificada à medida que as atividades do Grupo PET foram acontecendo. No desvelar de suas percepções sobre estas alterações chama atenção o valor que atribuem à atuação coletiva como aspecto positivamente relevante, indicando e reforçando seu valor para a composição do 'vir a ser professor'. 
A fim de aprofundar a compreensão sobre os saberes docentes e suas relações com a formação inicial e a atuação profissional, pedimos aos entrevistados que respondessem a seguinte questão: A partir das experiências ocasionadas pelo Grupo PET e baseada/o nas atividades vividas durante a graduação, quais são os principais problemas que você acredita que os professores das escolas enfrentam quando começam a trabalhar e precisam ser abordados pelos cursos de licenciatura?

Vinícius entende que os cursos de licenciatura precisam rever a integração da teoria com a prática, possibilitando, a partir das disciplinas responsáveis pelos estágios (Pesquisa e Prática de Ensino - PPE), uma experiência que proporcione esse contato direto com a realidade da escola.

Realmente, eu acho que pela experiência que eu tive nos cursos de licenciatura, inclusive no meu curso, é de que ele não prepara para a sala de aula. Porque como eu disse, a PPE acontece com uma estrutura totalmente ruim e esse é um grande problema. Não tô dizendo, assim, que o problema é só na PPE. Eu acho que deveria ser diferente, mas o problema de toda a integração entre as disciplinas de licenciatura e do bacharelado. O que vai resvalar na PPE, porque ali é um espaço de prática que acaba acontecendo de forma errada e a gente não vê as coisas como a gente vê no PET, sabe? Por exemplo, na disciplina de Didática eu fiz um plano de aula, mas eu não coloquei ele em prática [...]. No PET, eu fiz tudo isso! Eu planejei um projeto que são várias aulas integradas, eu implementei esse projeto. Então, eu sei o que deu errado, o que deu certo nele. Eu tive uma relação com os docentes da escola. Então, querendo ou não, dá para eu já ter uma noção de como é esse ambiente que não é um ambiente fácil. Muitos professores de primeira viagem sofrem muito às vezes não aguentam, têm problemas de saúde mental. Porque é pesado, não só aquele ambiente de sala de professor, mas a sala de aula. Então, eu também estive dentro da sala de aula, pude fazer esse trabalho em equipe. O que é muito importante e pouca gente tem essa oportunidade nesse meio (VINÍCIUS, 2018).

Nessa relação experiencial com o PET, Davi advertiu que a relação UniversidadeEscola é precária, sendo necessário repensar novas posturas, vislumbrando contribuir para a superação do que ele denomina 'solidão pedagógica'.

[...] a gente observa também, um grande número de evasão que ocorre dentro das licenciaturas que é algo assim, muito complicado. [...] Então, acho que o primeiro ponto é que a licenciatura tem que mostrar aos estudantes que é algo que não é fácil. Então, se você está escolhendo isso, você tem que ter a noção de que não vai ser fácil, vai ser desgastante, vai ser difícil e vai ser uma luta a cada dia. Então, após as licenciaturas apontarem e entenderem quais são os processos que precarizam a nossa prática, o que vem a sanar é uma luta coletiva pela escola pública, pela educação, pelo piso salarial adequado para o professor com plano de carreira. Mas além disso, talvez a palavra não seria um convênio, mas uma ponte entre Universidade e Escola, que o PET conseguiu fazer isso, que eu acho que o PIBID também consegue 
e outras políticas universitárias também conseguem, mas na minha opinião são mínimas, é de unir os dois mundos, as duas comunidades, a universitária e a escolar, entendendo-as como produtoras de conhecimento, produtoras de saberes e que elas não podem estar distantes. [...] A universidade presente na Escola e a Escola presente na Universidade, é possível pensar em meios, instrumentos e ferramentas que ajudem a sanar essa precarização do professor. Porque normalmente, ele sai da Universidade e entra na Escola Pública, algumas vezes ele assim, dá continuidade na sua formação, mas muitas vezes está desamparado pedagogicamente, psicologicamente, epistemologicamente e teoricamente. Então, a sua prática começa a ser somente a execução. E a Universidade, a partir desses projetos, os contatos de várias formas e de vários níveis dos licenciamentos com os professores com experiência ou aqueles que iniciaram de uma forma recente na Educação Básica, é extremamente importante para fortalecer a identidade docente [...]. Então, eu acho que a Universidade e a Escola se aproximando, vai contribuir muito para a melhoria dessa solidão pedagógica, dessa solidão docente [...] de uma forma assim, mais macro, no geral, a gente coloca assim, como crítica à Universidade, essa falta de ter contato na Escola [...] para construirmos processos formativos, processos de transformação da realidade educacional, que sim, parte deles e de nós, em coletivo [...] (DAVI, 2018).

Considerando o que foi exposto, podemos dizer que seria proveitoso envolver os licenciandos em atividades que contemplem mecanismos de formação de habitus profissional nos cursos de licenciatura?

Para Perrenoud (2001, p. 175), esse aspecto não pode ser negligenciado, tendo em vista que

[...] todos os mecanismos de formação interativos e todas as formas de cooperação e de trabalho de equipe podem não só estimular uma prática, mas também preparar condutas de explicação e [...] interpretação antes inscritas em um diálogo.

Partindo deste pressuposto e reconhecendo que "[...] em um ofício em que toda a cultura profissional prepara, sobretudo, para se trabalhar de porta fechada" (Idem), como é o caso do magistério, o pesquisador recomenda que a relação entre os sujeitos integrados ao campo de formação seja pautada por 'um contrato' no qual os partícipes estejam prontos para aprender entre si.

Corroborando essa afirmação, Davi ressaltou a importância do diálogo entre Universidade e Escola, considerando que a troca de experiências entre ambas contribuirá para o crescimento dos envolvidos. Considerou, ainda, que o distanciamento predominante em sua experiência como licenciando foi negativo, porque "[...] distanciou aqueles que têm experiência daqueles que contribuem para a construção do saber docente". 
Outro fator relevante apontado por Davi é a "evasão nas licenciaturas", também apresentado por Vinícius, onde afirma que ter uma bolsa de estudos pelo Programa contribuiu para sua permanência na Universidade, porém, deixou claro que o convívio com o Grupo e com a Tutora proporcionou uma relação de cumplicidade e diálogo, diferentemente da relação fria que na maioria das vezes acontecia na Universidade. Reconheceu que vivenciou de perto as carências da escola pública e os desafios com os quais o professor tem que se deparar, assumindo papéis para os quais não foi formado.

Está claro para você e para mim, também, de que tem total a ver. Eu acho que primeiro pela questão assim... já bati na tecla, a questão material, prática de ser uma bolsa. Uma bolsa que você pode levar até o final. E mais do que isso, falando mais especificamente do Grupo, da nossa tutora que colabora muito para isso. Ela é muito compreensiva, sabe? [...] Então, é isso! O PET foi importante pra minha permanência na universidade, acho que também pra muitos colegas que estiveram lá e que estão ainda. E trouxe a importância que a gente tem, dentro da sala de aula, pra permanência dos alunos na escola. Eu acho que isso é o mais importante (VINÍCIUS, 2018, grifo nosso).

Em nosso entendimento, contemplar e potencializar a relação Universidade-Escola pressupõe criar, na formação e no local de trabalho, condições que permitam ao futuro professor desenvolver-se profissionalmente 'a partir de', 'através de' e 'para a prática' (CHARLIER, 2001). Reconhecer que o futuro professor pode aprender 'a partir' da prática requer o entendimento de que esta se constituirá em ponto de partida e suporte da sua reflexão sobre a ação, seja em relação a sua própria prática ou a de seus colegas. Ele também poderá aprender 'através' quando for confrontado com a realidade, colocando-se como ator e interferindo nas exigências da situação, experimentando novas condutas e descobrindo soluções pertinentes à situação. E se o ponto de partida está na ação, aprenderá 'para a prática' na medida em que valorizar essencialmente os aprendizados que tiveram incidência direta sobre sua vida profissional (Idem).

Dito de outro modo, se desejo saber como realizar um trabalho ou utilizar o procedimento mais adequado preciso aprendê-lo com aqueles que efetuam esse trabalho. Tardif (2014) coaduna com esta perspectiva e acredita que nos próximos anos o principal desafio para a formação de professores será abrir maior espaço para os saberes práticos dentro da própria formação docente.

Diante dos depoimentos delineados, percebemos que a participação no Grupo PET parece ter sido relevante no que concerne à valorização da subjetividade dos seus participantes, ocasionada por meio do sentimento de liberdade e autonomia cultivados no 
andamento do trabalho. Neste cenário, o saber assume valor considerável, pois, deriva de um ato pessoal e ao mesmo tempo social, constituído em um processo coletivo e autobiográfico no qual o sujeito interfere e ressignifica as informações e os acontecimentos de acordo com as demandas que surgem, por meio do compartilhamento de ideias, da sua forma de ver o mundo e em elo com a finalidade de cada ação a ser adotada. Portanto, é na interação com o outro, a partir de suas estruturas cognitivas, culturais e emocionais, alterando a tradicional visão do papel da instituição escolarizada que se estabelecem pontes entre os sujeitos da aprendizagem e os saberes produzidos e mobilizados que permanecem em constante movimento (CUNHA, 2016; TARDIF, 2014).

\section{Considerações finais}

Embora os resultados desta investigação sejam instigantes, consideramos que aprimoramentos devem ser implementados ante o valor atribuído à sua metodologia e perante os insistentes questionamentos sobre o lugar das licenciaturas nas IES e na formação dos futuros professores da educação básica. O conjunto dos dados analisados, o estudo das obras selecionadas e nossa experiência como formadoras de professores nos levam a defender a ideia de que programas voltados para a formação docente são relevantes e necessários, servindo como importantes aliados aos cursos de licenciatura. Para tanto, é imprescindível que haja forte articulação com a escola pública, via configuração de acordos institucionais estabelecidos entre universidades, secretarias de educação e escolas, para os quais professores e alunos das instituições envolvidas sejam ouvidos e corresponsabilizados pela tessitura dos meandros desses acordos, tendo em vista os saberes acumulados e o domínio das especificidades regionais/locais que já possuem.

É com esta compreensão que consideramos o espaço formativo do Grupo PET Conexões de Saberes como campo propício ao desenvolvimento de aprendizagens sobre o ofício de professor, no qual os sujeitos têm a chance de constituir, revisar e formalizar saberes profissionais.

AGRADECIMENTOS: Agradecemos o apoio do Conselho Nacional de Pesquisa CNPq pelo suporte financeiro através da bolsa de estudos para a realização do Mestrado em Educação no PPGE/UFF. 


\section{REFERÊNCIAS}

BARDIN, L. Análise de conteúdo. Lisboa: Edições 70, 1996.

BRASIL. Decreto n. 7.219, de 24 de junho de 2010. Dispõe sobre o Programa Institucional de Bolsa de Iniciação à Docência - PIBID e dá outras providências. Diário Oficial da União, Brasília, DF, 25 jul. 2010.

CHARLIER, É. Formar Professores Profissionais para uma Formação Contínua Articulada à Prática. In: PAQUAY, L. et al. Formando professores profissionais: quais estratégias? quais competências? 2. ed. Porto Alegre: Artmed, 2001. p. 85-102.

CLANDININ, D. J.; CONNELLY, F. M. Narrative inquiry: experience and story in qualitative research. San Francisco: Jossey-Bass, 2000.

GATTI, B. Atratividade da carreira docente. Relatório de Pesquisa. São Paulo: Fundação Carlos Chagas; Fundação Victor Civita, 2009.

GATTI, B. Educação, escola e formação de professores: políticas e impasses. Educar em Revista, Curitiba, n. 50, p. 51-67, out./dez. 2013.

GATTI, B. Políticas de formação de professores. In: SCARELI, G. (Org.). Educação, culturas, políticas e práticas educacionais e suas relações com a pesquisa. Porto Alegre: Sulina, 2015.

GIL, A. C. Como elaborar projetos de pesquisa. 4. ed. São Paulo: Atlas, 2008.

LÜDKE, M; ANDRÉ, M. E. D. A. Pesquisa em educação: abordagens qualitativas. 8. ed. São Paulo: EPU, 2004.

MATTOS, C. L. G. de; CASTRO, P. A. de. Entrevista como instrumento de pesquisa nos estudos sobre fracasso escolar. In: SEMINÁRIO INTERNACIONAL DE PESQUISA E ESTUDOS QUALITATIVOS - PESQUISA QUALITATIVA: RIGOR EM QUESTÃO, 4., 2010, Rio Claro. Anais [...]. Rio Claro, 2010.

PERRENOUD, P. O Trabalho sobre o Habitus na Formação de Professores: análise das práticas e tomada de consciência. In: PAQUAY, L. et al. Formando professores profissionais: quais estratégias? quais competências? 2. ed. Porto Alegre: Artmed, 2001. p. 161-184.

SPINK, M. J. A produção de informação na pesquisa social: compartilhando ferramentas. In: ARAGAKI, S. S. (Org.). Entrevistas: negociando sentidos e coproduzindo versões de realidade. 1. ed. Rio de Janeiro: Centro Edelstein de Pesquisas Sociais, 2014. (Publicação virtual). Cap. 3.

TARDIF, M. Saberes docentes e formação profissional. 17. ed. Petrópolis, RJ: Vozes, 2014. 
VICENTE, M., VASCONCELLOS, M. Perspectivas em Diálogo. Revista de Educação e Sociedade, Naviraí, v. 01, n. 01, p. 43-54, jan./jun. 2014. Disponível em:

http://www.seer.ufms.br/index.php/persdia. Acesso em: 15 de janeiro de 2018.

\section{Como referenciar este artigo}

REZENDE, C. S. B.; VASCONCELLOS, M. Rememorar é transcender: um diálogo com licenciandos do Grupo PET Conexões de Saberes da Universidade Federal Fluminense. Revista Ibero-Americana de Estudos em Educação, Araraquara, v. 15, n. esp. 2, p. 15691584, ago. 2020. e-ISSN: 1982-5587. DOI: https://doi.org/10.21723/riaee.v15iesp2.13829

Submetido em: 30/08/2019

Revisões requeridas: $30 / 11 / 2019$

Aprovado em: 02/02/2020

Publicado em: 01/08/2020 